\title{
Application of Visual Simulation Technology in College English Teaching
}

\author{
LIU Yalan \\ Zhong shan Vocational College, Nanjing 210049, China \\ LiuYalan1012@yeah.net
}

Keywords: visual simulation technology; college English; Applications

\begin{abstract}
As an international language, English occupies an important position in university language courses. While English has the same abstract features as other languages, so how to make English teaching more vivid and improving students' interest in learning English has become a key point in English teaching model reforms. Visual simulation technology solves this problem effectively.
\end{abstract}

\section{Introduction}

Currently visual simulation technology has achieved widespread application in the field of military exercises, urban planning, etc. With the reform of college English teaching mode, visual simulation technology also has tentative applications in the field of education.

\section{Analysis of visual simulation technology}

\section{The Understanding of Visual Simulation Technology}

As an important form of expression of virtual reality technology, visual simulation technology came into being on the basis of the innovation and development on simulation animation. It has a definite simulation purpose, relying on computer graphics technology, and use appropriate computer software to create a three-dimensional model of simulation object or to reproduce the real environment.

\section{Features of Visual Simulation Technology}

1) Comprehensive. Comprehensive mainly refers to the integrated use of a variety of high-tech, including computer technology, audio technology, image processing technology, synthetic technology and visual display technology.

2) Interaction. Users of visual simulation technology are able to exchange information with the virtual objects in the virtual environment, such as the operable degree of virtual objects, the movement degree of virtual objects by natural law and the degree of information feedback users obtained from virtual environment. Visual simulation technology can be said to directly embody the idea of human-machine harmony.

3) Authenticity. Although visual simulation technology is creating a virtual scene, due to its high fidelity, it can give users an immersive feel. Trying to improve the authenticity of the virtual scene is also the fundamental purpose of simulation technology.

4) Associative. Associative refers to more intuitive feelings users can get in such a realistic environment, improving their knowledge and understanding of English, improving the ability to use English, thus thinking of more content to generate new ideas.

5) Convenience. The application of visual simulation technology is not limited by time and space, so the user can arrange their own time to use it at any time.

\section{The Process of Visual Simulation}

1) Prepare materials

To collect materials according to the needs of English teaching and learning, such as satellite photos, size and shape of three-dimensional objects, digital maps and so on.

2) Data prepossessing

According to the general design requirements, determine specific indicators and optimize raw 
data . For example, use relevant software to build the continuous natural terrain. At the same time, use software such as 3dmax to build a three-dimensional object model, and finally process and optimize data structure and texture.

3) Creating simulation environment

The procedure for creating simulation environment is: designing a three-dimensional model of simulation object, creating simulation scenarios, designing and creating realistic texture, designing simulation effects.

4) Simulation driven

Simulation driven mainly includes the following steps: simulation scene driven, adjusting and processing the three-dimensional simulation model by requirements, distribution cross, large terrain processing.

5) Try on debug

After the finish of simulation environment modeling, tried by professionals and they strictly record trial for unified analysis and process to optimize the simulation environment as much as possible. Officially put into use after commissioning.

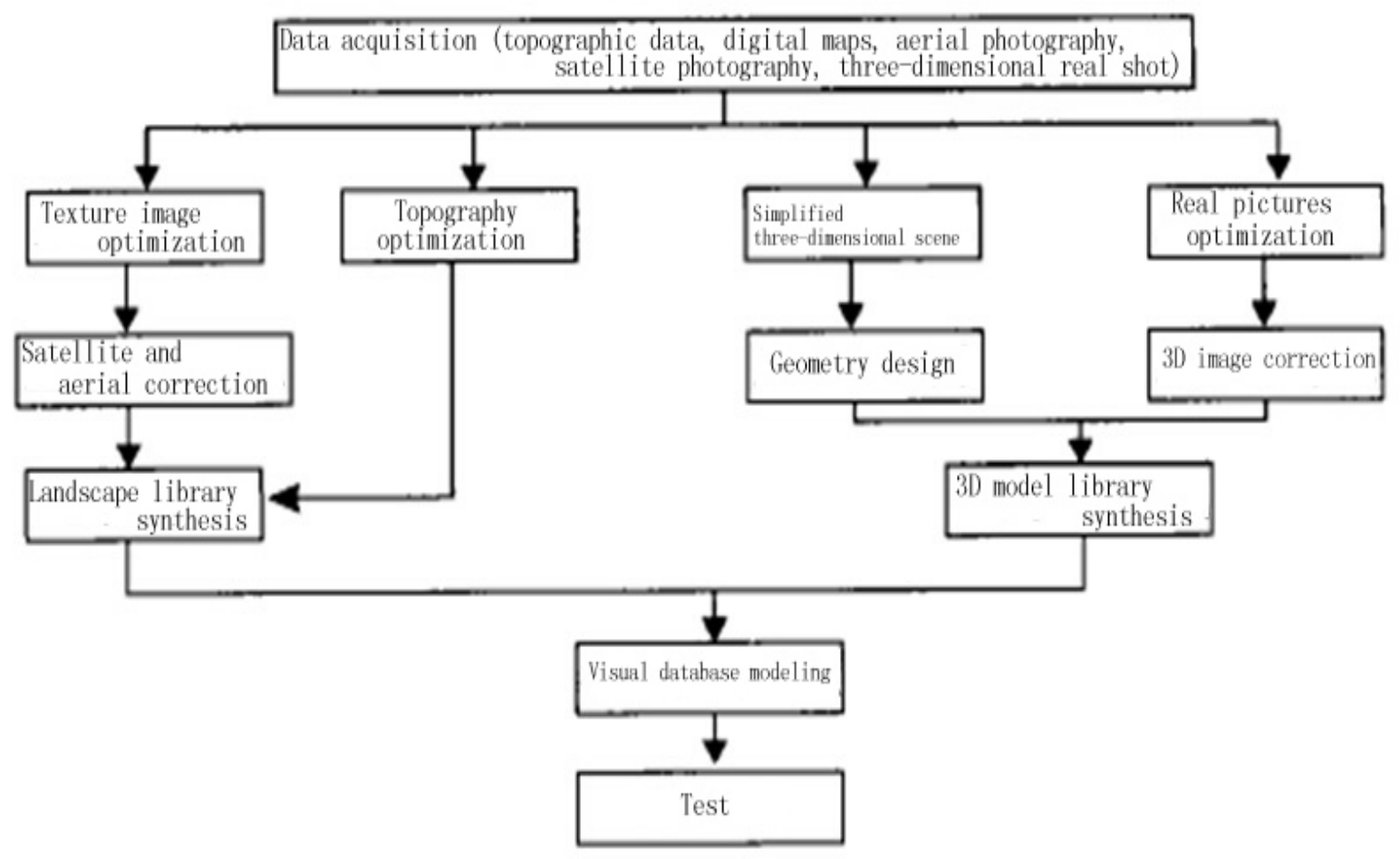

Figure 1 Visual simulation modeling flow chart

\section{Applications of visual simulation technology in college English teaching \\ The significance of the applications of visual simulation technology in college English teaching applications}

1) Interactive learning

The application of visual simulation technology into college English teaching has changed the original single classroom teaching mode. Modern virtual technology can create an English virtual world, Students no longer only passively accept English knowledge. Learning in the simulation environment can actively dialogue with virtual characters in English and effectively improve students' oral proficiency. In addition, scene environmental effects simulation and control such as clouds, fog, light and so on, can give students a real time and sense of scene change to adapt to different dialogue plot, thus deepening the understanding for dialogue.

2) Situational awareness

Language learning itself is abstract, especially English as a second language is more difficult to 
understand for Chinese college students. Simulation technology can simulate a virtual English environment for college students and students in this environment feel like being in real English-speaking countries, thus deepening students 'awareness and understanding of English culture, therefore promoting students' ability to understand English.

\section{3) Fun learning}

Visual simulation environment fully bond together education and the game. students learn academic knowledge by solving the problems and challenges in numbers game to learn subject knowledge. Visual simulation technology achieves a many-to-one teaching model on the basis of breaking the original one-to-many teaching mode. While students in the simulation environment will not be bound by classroom learning, so that learning English is no longer a staid, boring thing and it ensures students learn English with a relaxed state of mind.

\section{4) Application location}

Visual simulation English learning system is mainly used in professional English classroom scenarios teaching emphasizing embodiment, such as tourism English, foreign trade English, children's English and so on. The biggest difference between the system and Second Life, the open network virtual reality system is curriculum. The system not only provides simulation scenarios experience for students, but also do experience testing for learning outcomes of students within a certain time.

\section{Implementation steps of visual simulation technology in college English teaching}

1) Background teaching. According to the learning materials given by teachers and learning objectives, independently formulate vocabulary, grammar, oral expression, cultural understanding of English and other learning tasks.

2) Activities research. Students can spontaneously form study group, gather learning resources in small groups with collaborative approach, access to relevant learning content through the library, the Internet and other channels and analyze it to prepare for the experiential learning of simulation scenarios.

3) Scenario experience. Students in the classroom or independently enter into the visual simulation system and create a virtual character to complete the learning carried out in the form of game-based task. What should be noted here is the game-based task can be set to the appropriate assessment content, so that it can not only achieve the purpose of teaching, but also allows teachers to fully understand each student's learning.

4) Case studies. Teachers select more representative scenario experience videos to comment in the classroom. For example, for a general mistake, teachers can choose a more representative video content to make a depth analysis and timely help students solve problems encountered in the learning process.

5) Teaching reflection. After performing targeted case analysis, teachers can upload the video to the school website again. Students can study by downloading and viewing the video to looking for a lack of knowledge on their own and focus on learning their poor grasped knowledge.

6) Summarization. Students rethink the process and results of scenario experience and write summaries of visual simulation teaching in accordance with their own learning outcomes.

\section{Conclusion}

In summary, realistic visual effect and good interaction are the most significant characteristics of visual simulation technology. It can create different virtual scenarios according to the teaching goals and effectively improve the quality of college English teaching. Therefore, we must vigorously promote the application of visual simulation technology in college English teaching and believe visual simulation technology has even broader prospects in the field of English education.

\section{References}

[1] Chen Guiqin. Intercultural Teaching Problems and Solutions in University English [D]. Shanghai International Studies University, 2014. 
[2] Xiang Shiyou. Application of Multimedia Technology in College English Teaching [J]. Heilongjiang Science and Technology Information, 2008, 09: 124.

[3] Zhu Lei, Zhang Jianqing. Application of Visual Simulation Technology in Business English Project Learning [J]. China Educational Technology, 2011, 12: 110-113.

[4] Zhou Wei. Visual Simulation Technology in Vocational Training Teaching English for Tourism Exploratory Application [J]. Contemporary Vocational Education, 2013, 09: 35-37 + 80.

[5] Li Hongcai, Yan Qingdong, Wang Tao. Application of Visual Simulation Technology in Teaching Practice [J]. Experimental Technology and Management, 2010, 10: 94-97 + 100. 